\title{
Caracterização do Gene da Proteína Capsidial do Grapevine virus A em Videiras Afetadas pela Acanaladura do Lenho de Kober no Estado de São Paulo*
}

\author{
Andreia E. Moreira ${ }^{1}$, José O. Gaspar ${ }^{1 * *}$, Luis E. A. Camargo ${ }^{2} \&$ Hugo Kuniyuki $^{3 * *}$ \\ ${ }^{1}$ Departamento de Zoologia e Botânica, IBILCE-UNESP, CEP 15054-000, São José do Rio Preto, SP, e-mail: \\ gaspar@dzb.ibilce.unesp.br; ${ }^{2}$ Departamento de Entomologia, Fitopatologia e Zoologia Agrícola, ESALQ-USP, Cx. Postal 9 , \\ CEP 13418-900, Piracicaba, SP; ${ }^{3}$ IAC-Centro de Pesquisa e Desenvolvimento de Fitossanidade, CEP 13020-902, Campinas, SP
}

(Aceito para publicação em 06/01/2004)

Autor para correspondência: José Osmar Gaspar

MOREIRA, A.E., GASPAR, J.O., CAMARGO, L.E.A. \& KUNIYUKI, H. Caracterização do gene da proteína capsidial do Grapevine virus A em videiras afetadas pela acanaladura do lenho de Kober no Estado de São Paulo. Fitopatologia Brasileira 29:205-208. 2004.

\section{RESUMO}

O presente trabalho caracteriza o gene codificador da proteína capsidial do isolado do Grapevine virus A (GVA) encontrado no Estado de São Paulo (GVA-SP). RNA total foi extraído de folhas e pecíolos de plantas de videira (Vitis spp.) da variedade 'Kober 5BB' e submetido a RT-PCR usando oligonucleotídeos desenhados para amplificar um fragmento entre as posições 6409 e 7175 do RNA do GVA ("GenBank", acesso X75433). Foi obtido um fragmento de tamanho esperado (767 nt) que inclui o gene da proteína capsidial, codificando 198 aminoácidos. A seqüência do GVA-SP apresentou similaridade de nucleotídeos e aminoácidos de, respectivamente, 86-92,3\% e 94,598\% com isolados do GVA da Europa, África e Japão (Acessos X75433, AF441234, AF007415, AB039841) e da região Sul do Brasil (Acesso AF494187), sendo, entretanto, mais similar aos isolados africano e italiano.

Palavras-chave adicionais: GVA, Vitivirus, Vitis spp., "Kober stem grooving", complexo do lenho rugoso, seqüenciamento, filogenia.

\section{ABSTRACT}

Characterization of the coat protein gene of Grapevine virus $A$ from Kober stem grooving-affected grapevines in the State of São Paulo, Brazil

We report the characterization of the coat protein gene of a Brazilian isolate of Grapevine virus A (GVA-SP). Total RNA was extracted from leaves and petioles of GVA infected plants of the grape (Vitis spp.) variety 'Kober 5BB' and subjected to RT-PCR using primers designed to amplify a fragment between positions 6409 and
7175 of the GVA RNA (GenBank Accession X75433). A fragment of the expected size (767 nt) was obtained which included the coat protein gene coding for 198 amino acids. The GVA-SP sequence displayed nucleotide and amino acid similarity of, respectively, 8692.3\% and 94.5-98\% with GVA isolates from Europe, Africa and Japan (Accessions X75433, AF441234, AF007415, AB039841) and Southern Brazil (Accession AF494187). The highest identity, however, was with the African and Italian isolates.
As viroses representam um dos mais importantes problemas fitossanitários da viticultura mundial, ocorrendo em praticamente todas as regiões onde a videira (Vitis spp.) é cultivada. De modo geral, essas doenças caracterizam-se por induzir lenta e gradual degenerescência da planta, causando constantes perdas na produção de uva, que chegam a perdas totais em variedades mais sensíveis (Amorim \& Kuniyuki, 1997).

No Brasil, as principais viroses da videira já foram constatadas, tais como o enrolamento da folha ("grapevine leafroll", GLR), mosaico das nervuras ("grapevine fleck disease", GFkD), folha em leque ("grapevine fanleaf”, GFL) e o complexo do lenho rugoso ("grapevine rugose wood", GRW) (Amorim \& Kuniyuki, 1997). O GRW é um termo usado para designar um grupo de doenças caracterizadas por

\footnotetext{
*Apoio financeiro: FAPESP e CAPES. Seqüência depositada no GenBank

com o número de acesso AY340581

**Bolsistas de produtividade do CNPq
}

causar alterações no lenho de plantas afetadas de variedades sensíveis. É constituído por, pelo menos, quatro doenças diferentes: fendilhamento cortical ("grapevine corky bark", GCB), cascudo ou lenho estriado ("Rupestris stem pitting", RSP), acanaladura do lenho de Kober ("Kober stem grooving", KSG) e acanaladura do lenho de LN-33 ("LN-33 stem grooving", LNSG) (Savino et al., 1989; Minafra, 2000), sendo todas elas constatadas no Brasil (Kuniyuki, 1972; Amorim \& Kuniyuki, 1997; Kuniyuki et al., 2001; Kuhn et al.,2002).

Os sintomas gerais do complexo do lenho rugoso da videira consistem em atraso na brotação de primavera, redução de vigor, baixa produção de uva, intumescência na região acima do ponto de enxertia e uma evidente diferença nos diâmetros do lenho da copa e do porta-enxerto, casca espessa e corticosa, com textura esponjosa e caneluras ("pittings") e/ ou acanaladuras ("groovings") no lenho, que correspondem a saliências na superfície cambial da casca. Essas alterações ocorrem em variedades de copa, porta-enxerto ou ambos. A 
intensidade desses sintomas, principalmente no lenho, parece depender da combinação copa/porta-enxerto. Não existem sintomas específicos nas folhas, mas, em algumas variedades, elas tornam-se avermelhadas ou amareladas e com enrolamento dos bordos foliares. Algumas variedades mais sensíveis apresentam declínio e morte, depois de poucos anos após o plantio. Muitas variedades produtoras de uva e de porta-enxerto apresentam infecção latente dos agentes causais do complexo. As doenças que compõem o complexo do lenho rugoso não podem ser facilmente distinguidas no campo, devido à ausência de sintomas específicos. A identificação das doenças é feita usando três indicadoras diferenciais, que são Kober 5BB, LN-33 e V. rupestris (Amorim \& Kuniyuki, 1997).

$\mathrm{O}$ “Kober stem grooving" (KSG) é identificado apenas com base nos sintomas de acanaladuras ou sulcos longos no lenho de plantas afetadas da videira indicadora Kober 5BB, não apresentando sintomas em $V$. rupestris e em LN-33. O KSG é atribuído ao vírus A da videira (Grapevine virus A, GVA) (Garau et al., 1994; Choueiri et al., 1997). No Brasil, a doença foi constatada, pela primeira vez, em 1992, em plantas com declínio de 'Niagara Rosada' em Jundiaí, SP (Kuniyuki \& Costa, 1992) e, mais recentemente, a associação do GVA com essa doença foi reforçada pelo teste de ELISA (Kuniyuki et al, 2001).

O GVA, espécie tipo do gênero Vitivirus (Martelli et al., 1997), apresenta partículas filamentosas de aproximadamente $800 \mathrm{~nm}$ de comprimento e genoma constituído por uma molécula de RNA de fita única e polaridade positiva com 5 "open reading frames" (ORF) (Minafra et al., 1994). O vírus tem a videira como única hospedeira natural, estando restrito ao floema desta. É perpetuado principalmente através de multiplicação vegetativa, por estaquia ou união de tecidos e transmitido naturalmente por espécies de cochonilhas brancas (Pseudococcus e Planococcus). Pode ser transmitido mecanicamente, com grande dificuldade, para algumas espécies de Nicotiana (Martelli et al., 1997).

No presente trabalho, descreve-se a caracterização do gene codificador da proteína capsidial de um isolado do GVA encontrado no Estado de São Paulo (GVA-SP). Esse isolado foi inicialmente obtido de uma planta da variedade Niagara Rosada da região de Jundiaí, SP (Kuniyuki \& Costa, 1992) e que, por ter induzido sintomas característicos do KSG em 'Kober 5BB', vem sendo mantido nesse porta-enxerto indicador, em canteiro, no Instituto Agronômico de Campinas.

A extração de RNA totais foi feita a partir do portaenxerto 'Kober 5BB' ( $V$. berlandieri $x$ V. riparia), infetado pelo GVA e com sintomas de acanalamento do lenho, utilizando-se o método de MacKenzie et al. (1997). Em linhas gerais, amostras de tecido ( $1 \mathrm{~g}$ de nervuras e pecíolos) foram congeladas com $\mathrm{N}_{2}$ líquido, trituradas a pó e extraídas com 5,0 ml de tampão (guanidina $4 \mathrm{M}$, acetato de sódio $0,2 \mathrm{M}$ pH 5,0, EDTA $25 \mathrm{mM}$ e PVP-40 2,5\%), 0,5 ml de Sarcosil $20 \%$ e $0,05 \mathrm{ml}$ de 2?-Mercaptoetanol. A mistura foi aquecida a $70{ }^{\circ} \mathrm{C}$ por $10 \mathrm{~min}$, resfriada à temperatura ambiente e aplicada à coluna do "RNeasy Plant Mini Kit" conforme especificação do fabricante (Qiagen).

Para a síntese de DNA complementar (cDNA) foram utilizados os oligonucleotídeos CN47, CN54 e CN55, contendo 21 timinas antecedidas, respectivamente, por A, C ou G (Pappu et al., 1993) complementares à cauda poliadenilada da região 3' terminal do RNA viral. Na reação (20 ?1), inicialmente foi feita a desnaturação do RNA total (200 ng) e dos oligonucleotídeos (10 ? g/ml cada) por aquecimento a 95 ${ }^{\circ} \mathrm{C}$ por $5 \mathrm{~min}$ e posterior resfriamento em gelo/álcool. Em seguida, foram adicionados os demais componentes: tampão (Tris-HCl $50 \mathrm{mM} \mathrm{pH} 8,3$ e KCl $5 \mathrm{mM}$ ), DTT $10 \mathrm{mM}, \mathrm{MgCl}_{2}$ $3 \mathrm{mM}, 0,2 \mathrm{mM}$ de cada dNTP (dCTP, dGTP, dATP e dTTP), uma unidade de inibidor de RNAse e 200 unid. de transcriptase reversa (Superscript II RNAse H; Gibco-BRL). A mistura foi incubada a $42^{\circ} \mathrm{C}$ por $2 \mathrm{~h}$.

Com base na seqüência do isolado italiano do GVA (Minafra et al., 1994), dois pares de oligonucleotídeos foram desenhados utilizando os programas Primer-3 e Oligo-4. Juntos, estes dois pares incluem todo o gene codificador da proteína capsidial (597 nucleotídeos). O par denominado GVA1 amplifica uma seqüência de 430 nucleotídeos (nt 6409 ao 6839) (sense: 5' GACAAATGGCACACTAGG 3', antisense: 5' AAGCCTGACCTAGTCATCTTGG 3') e o par denominado GVA2 amplifica uma seqüência de 391 nucleotídeos (nt 6784 ao 7175) (sense: 5' GGCTGAAATGGGCACA TACT3'; anti-sense: 5'CCCTCTTTCACGAACCGTAA3').

Para a amplificação pela reação em cadeia pela polimerase ("Polymerase Chain Reaction", PCR) utilizou-se um volume de 50 ? 1 consistindo de tampão (Tris- $\mathrm{HCl} 20 \mathrm{mM}$ pH 8,4; $\mathrm{KCl} 50 \mathrm{mM}$ ), 3,5 mM de $\mathrm{MgCl}_{2} ; 0,2 \mathrm{mM}$ cada dCTP, dGTP, dATP e dTTP, 10 ? g/ml de cada oligonucleotídeo (sense e anti-sense), 2 ?1 da mistura da reação de cDNA e três unidades de Taq DNA polimerase (Invitrogen). O ciclo da PCR envolveu uma desnaturação inicial a $94{ }^{\circ} \mathrm{C}$ por 4 min e 30 ciclos com 1 min de desnaturação a $94^{\circ} \mathrm{C}, 1$ min de anelamento dos oligonucleotídeos a $53{ }^{\circ} \mathrm{C}$ e 2 min de extensão a $72{ }^{\circ} \mathrm{C}$. Após os 30 ciclos, seguiu-se uma extensão final por $10 \mathrm{~min}$ a $72{ }^{\circ} \mathrm{C}$. Os fragmentos amplificados foram visualizados em gel de agarose $1 \%$ corado com brometo de etídio $(1 ? \mathrm{~g} / \mathrm{ml})$ sob luz ultravioleta.

A clonagem dos fragmentos obtidos foi feita utilizandose o "TOPO TA Cloning Kit" segundo instruções do fabricante (Invitrogen) e a extração do plasmídeo recombinante realizada utilizando-se o "Concert Rapid Plasmid Miniprep System Kit" (Gibco-BRL). Após a extração do DNA plasmidial das células selecionadas, foram feitas digestões enzimáticas para a comprovação da formação do recombinante. O seqüenciamento em ambas as direções foi feito utilizando-se os oligonucleotídeos universais M13 e o "DNA sequencing Kit Big-Dye Terminator Cycle Sequencing Ready Reaction" (Perkin Elmer) em um sequenciador ABI Prism 377 (Applied Biosystems, Inc). A análise comparativa das sequiências foi feita através do algoritmo BLAST (http://www.ncbi.nlm.nih.gov) e o alinhamento das seqüências consenso pelo programa Multalin (http://prodes.toulouse.inra.fr/multalin/multalin.html). A seqüência de aminoácidos deduzidos da proteína capsidial foi 
Caracterização do gene da proteína capsidial do Grapevine virus A...

determinada pelo programa Translate (http://www.expasy.org/ tolls/dna.html). As relações filogenéticas foram determinadas por parcimônia com auxílio do software PAUP v.4.0b10 com análise de "bootstrap" de 500 réplicas. A construção gráfica da árvore foi feita pelo programa Tree View 1.6.1.

Os RNA extraídos de videiras infetadas pelo GVA-SP permitiram a amplificação de fragmentos de tamanhos esperados (GVA1: 430 pb?GVA2: $391 \mathrm{pb}$ ), não havendo amplificação a partir de plantas não infetadas (dados não mostrados). Os fragmentos amplificados foram clonados e seqüenciados. A seqüência obtida apresentou 767 nucleotídeos, dos quais 597 correspondiam ao gene codificador da proteína capsidial (CP) do GVA-SP (Figura 1). A sequiência deduzida de aminoácidos para essa proteína constou de 198 resíduos e massa molecular estimada em $21.650 \mathrm{Da}$, valor similar a outros isolados do GVA (Minafra et al. 1994?Fajardo et al., 2003).

A sequiência de nucleotídeos da CP do GVA-SP, quando comparada com isolados de outras regiões geográficas (Tabela 1), revelou maior identidade com um isolado da África do Sul (GVA-AF, 92,3\%) e da Itália (GVA-IT, 92\%) e menor identidade com um isolado de Israel (GVA-IS, 86\%). Em relação ao outro isolado brasileiro do Rio Grande do Sul (GVA-RS), a identidade foi de $88 \%$. No entanto, quando foi comparada a sequiência deduzida de aminoácidos do GVA-SP com a dos outros isolados, a identidade variou de $94,5 \%$ a $98 \%$ (Tabela 1) indicando que a maioria das trocas de nucleotídeos observadas são sinônimas, não envolvendo mudanças no aminoácido especificado e, portanto, não alterando significativamente a proteína codificada.

Foram realizadas análises filogenéticas por parcimônia para a seqüência de nucleotídeos (Figura 2A) e aminoácidos (Figura 2B) dos isolados do GVA e outras espécies do recém criado gênero Vitivirus, cujas proteínas capsidiais já haviam sido sequienciadas. A análise conjunta das duas árvores permite concluir que a espécie que apresenta maior similaridade com o GVA dentro do gênero é o vírus D da videira (Grapevine virus $D, G V D$ ), sendo ambos agrupados em um mesmo ramo ("bootstrap" =100). Essa proximidade genética entre GVA e GVD já havia sido relatada em outros trabalhos (Choueiri et al., 1997; Fajardo et al., 2003), em oposição aos testes que revelaram uma fraca reação sorológica entre esses dois vírus (Martelli, 1997). As outras duas espécies analisadas, vírus B da videira (Grapevine virus B, GVB) e Heracleum latent virus (HLV), ocupam posições mais distantes na árvore em relação ao GVA.

Em relação à análise filogenética da seqüência de nucleotídeos, os isolados do GVA formam um grupo monofilético no qual GVA-SP e GVA-AF são agrupados em um mesmo ramo indicando origem comum. Em seguida situamse os isolados do Rio Grande do Sul e da Itália, que estão bem próximos entre si confirmando dados anteriormente publicados (Fajardo et al. 2003). Já os isolados GVA-JPe GVA-IS são os que mais se distanciam do isolado paulista. $\mathrm{Na}$ análise filogenética da sequiência deduzida de aminoácidos da $\mathrm{CP}$, todos os isolados são agrupadas em um mesmo ramo o que

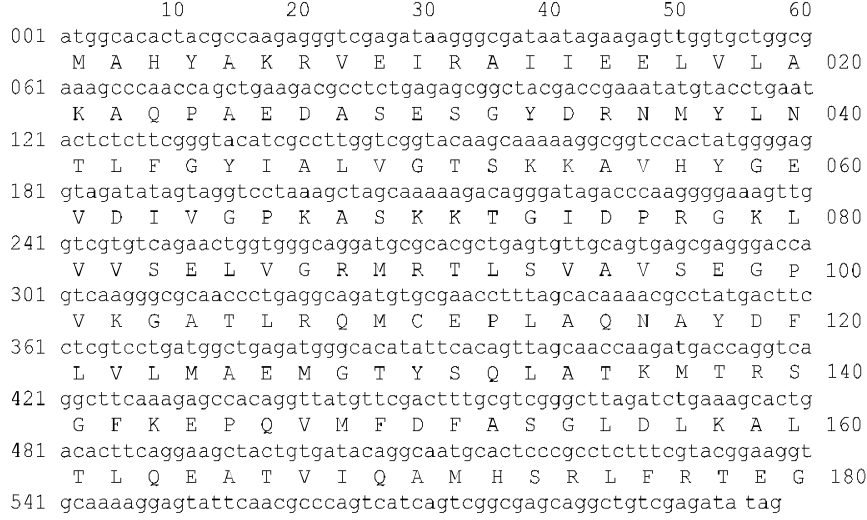

FIG. 1 - Sequiência de nucleotídeos (superior) e aminoácidos deduzidos (inferior) do gene da proteína capsidial do Grapevine virus A (GVA-SP).

leva novamente a inferir que, apesar das variações mais acentuadas na sequiência de nucleotídeos, a proteína capsidial parece apresentar pouca variação entre os isolados de regiões geográficas distintas. Considerando ser essa uma proteína estrutural, fatores evolutivos poderiam estar restringindo as variações que seriam deletérias para a espécie. Alterações na proteína capsidial poderiam, por exemplo, levar à perda de interação com a hospedeira e o fato do GVA ter como única hospedeira natural a videira, estaria restringindo ainda mais essas alterações.

A viticultura brasileira resulta da introdução de variedades de copa e porta-enxerto oriundas principalmente de países como Estados Unidos, França e Itália (Sousa, 1996). Contudo, nas regiões dos Estados Unidos, onde são cultivadas variedades e híbridos de Vitis labrusca L. (Concord, Isabel, Niagara), a incidência de viroses tem sido limitada, pois essas são de cultivo mais recente do que as viníferas. Assim sendo, pode-se inferir que os vírus constatados até o presente no Brasil foram introduzidos daqueles países europeus e, por

TABELA 1 - Comparação (similaridade em porcentagem) entre seqüências de nucleotídeos (abaixo da diagonal, em cinza) e aminoácidos deduzidos (acima da diagonal) da proteína capsidial do isolado paulista do Grapevine virus A (GVA-SP, AY340581) e outros isolados depositados no GenBank*

\begin{tabular}{|c|c|c|c|c|c|c|}
\hline & 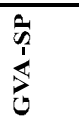 & $\begin{array}{l}E^{(1)} \\
\sum^{4} \\
0\end{array}$ & 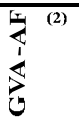 & $\begin{array}{l}\mathscr{n}^{(3)} \\
\underbrace{\frac{1}{4}} \\
0\end{array}$ & $\hat{i}^{(4)}$ & 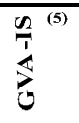 \\
\hline GVA-SP & --- & 97 & 98 & 94,5 & 97 & 97 \\
\hline GVA-IT ${ }^{(1)}$ & 92 & --- & 97,5 & 95,5 & 97 & 97 \\
\hline GVA-AF ${ }^{(2)}$ & 92,3 & 91,3 & --- & 94,9 & 98 & 96,5 \\
\hline GVA-RS ${ }^{(3)}$ & 88 & 90 & 89,1 & -- & 95,5 & 95,5 \\
\hline GVA-JP( ${ }^{(4)}$ & 88 & 89 & 87,1 & 85 & --- & 98 \\
\hline GVA-IS ${ }^{(5)}$ & 86 & 88 & 86,4 & 85 & 85 & --- \\
\hline
\end{tabular}

(1) Isolado da Itália (X75433.1); (2) Isolado da África do Sul (AF441234); (3) Isolado do Rio Grande do Sul (AF494187.1); (4) Isolado do Japão (AB039841.1); (5) Isolado de Israel (AF007415).*Os códigos de acesso no GenBank estão indicados entre parênteses. 
A

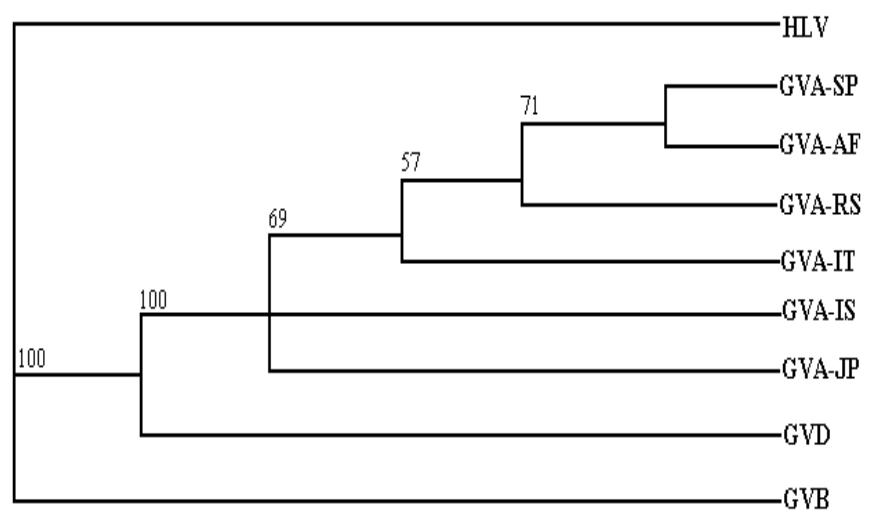

B

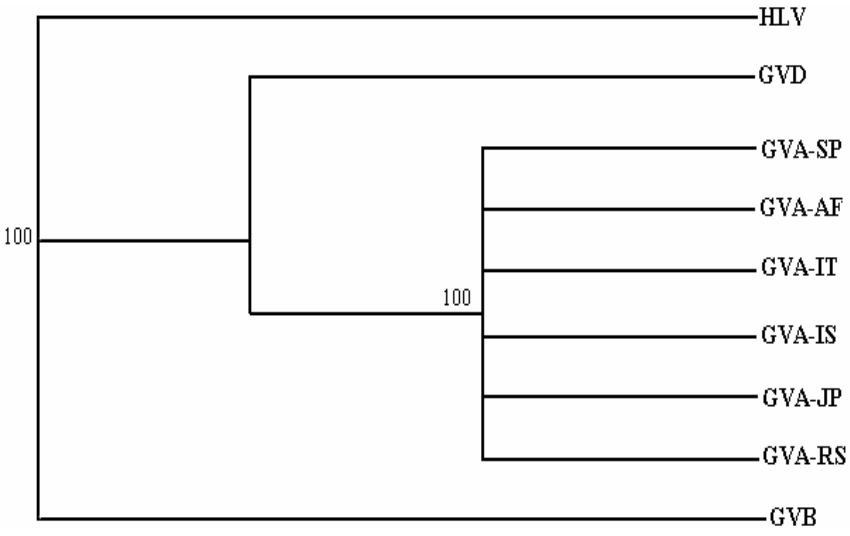

FIG. 2 - Análise filogenética por parcimônia com base na seqüência completa de nucleotídeos (A) e aminoácidos deduzidos (B) da proteína capsidial dos isolados do Grapevine virus $A$ (GVA) e de outras espécies do gênero Vitivirus. Os números de acesso ao GenBank para os vírus citados acima são: GVA-SP (AY340581), GVA-IT (X75433.1), GVA-AF (AF441234), GVA-RS (AF494187.1), GVA-JP (AB039841.1), GVA-IS (AF007415), GVD (Y07764), HLV (X79270), GVB (AY340582).

conseguinte, é possível afirmar que GVA-SP e GVA-RS possuem origem semelhante.

$\mathrm{Na}$ África do Sul, a incidência de vírus é próxima aos $100 \%$, sendo explicada pela utilização de porta-enxertos de origem européia a partir do século vinte (Sousa, 1996). A alta identidade observada entre os isolados do GVA de São Paulo e da África do Sul parece indicar uma possível origem comum entre eles, decorrente da introdução de material propagativo infetado, provavelmente oriundo da Itália, devido a identidade de ambos com o GVA-IT.

É importante ainda ressaltar que, nos testes efetuados neste trabalho, a técnica de RT/PCR permitiu uma rápida e sensível detecção do GVA, podendo ser utilizada como técnica alternativa para futuros diagnósticos.

\section{REFERÊNCIAS BIBLIOGRÁFICAS}

AMORIM, L. \& KUNIYUKI, H. Doenças da videira. In: Kimati, H., Amorim, L., Bergamin, A., Camargo, L.E.A., Rezende \& J.A.M. (Eds) Manual de Fitopatologia, vol.2: Doenças de plantas cultivadas. São Paulo. Agronômica Ceres. 1997. pp.736-757.

CHOUEIRI, E., DIGIARO, M. \& SAVINO, V. Further evidence that Grapevine virus A is the agent of Kober stem grooving. Extended Abstracts, $12^{\text {th }}$ Meeting of the International Council for the Study of Viruses and Virus-like Diseases of the Grapevine (ICVG), Lisboa, Portugal. 1997. p.39.

FAJARDO, T.V.M., NICKEL, O., EIRAS, M. \& KUHN, G.B. Detecção de um isolado de Grapevine vírus A e caracterização do gene da proteína capsidial. Fitopatologia Brasileira 28:521-527. 2003.

GARAU, R., FROTA, V. A., PIREDDA, A., BOSCIA, D. \& PROTA, $\mathrm{U}$. On the possible relationship between Kober stem grooving and grapevine virus A. Vitis 33:161-163. 1994.

KUHN, G. B., FAJARDO, T.V.M. \& NICKEL, O. Detecção biológica de três vírus do complexo rugoso da videira causadores de caneluras. Fitopatologia Brasileira 27:207. 2002 (Resumo).

KUNIYUKI, H. Nota sobre a ocorrência do "cascudo", moléstia semelhante ao "legno riccio" em São Paulo. Revista Brasileira de Fitopatologia 5:137. 1972 (Resumo).

KUNIYUKI, H. \& COSTA, A. S. Caneluras no porta-enxerto Kober 5BB são provavelmente causadas por um novo isolado do vírus do cascudo da videira. Summa Phytopathologica 18:13. 1992 (Resumo). KUNIYUKI, H., REZENDE, J.A.M, YUKI, V.A. \& BETTI, J.A. Detecção serológica do Grapevine virus A em vinhedos do Estado de São Paulo. Summa Phytopathologica 27:116-117. 2001 (Resumo).

MACKENZIE, D.J., MCLEAN, M.A., MUKERJI, S. \& GREEN, M. Improved RNA extraction for woody plants for the detection of viral pathogens by Reverse Transcription-Polymerase Chain Reaction. Plant Disease 81:222-226. 1997.

MARTELLI, G.P., MINAFRA, A. \& SALDARELLI, P. Vitivirus, a new genus of plant viruses. Archives of Virology 142:1929-1932. 1997.

MINAFRA, A., SALDARELLI, P., GRIECO, F. \& MARTELLI, G.P. Nucleotide sequence of the 3' terminal region of the RNA of two filamentous grapevine viruses. Archives of Virology 137:249-261. 1994.

MINAFRA, A. Rugose wood of grapevines. Extended Abstracts, $13^{\text {th }}$ Meeting of the International Council for the Study of Viruses and Virus-like Diseases of the Grapevine (ICVG), Adelaide, Australia. 2000. pp 30-34.

PAPPU, S.S., BRAND, R. \& PAPPU, H.R. A polymerase chain reaction method adapted for selective amplification and cloning of 3 'sequences of potyviral genomes: application to dasheen mosaic virus. Journal Virological Methods 41:9-20, 1993.

SAVINO, V., BOSCIA, D. \& MARTELLI, G.P. Rugose wood complex of grapevine: can grafting to Vitis indicators discriminate between diseases? Proceedings, $9^{\text {th }}$ Meeting of the International Council for the Study of Viruses and Virus-like Diseases of the Grapevine (ICVG), Kiryat Anavim, Israel. 1989. pp.91-94.

SOUSA, J.S.I. Uvas para o Brasil. FEALQ, v.1.1996. 